inappropriate choice of risk estimates, imprecision in the risk estimates and estimates of proportions exposed, inaccurate risk exposure period and latency assumptions and a lack of separate risk estimates in some cases for women and/or cancer incidence. However, the results form a robust basis on which to carry out a socio-economic comparison of the health benefits and costs of compliance.

\section{MINISYMPOSIUM OF THE SHECAN PROJECT - METHODOLOGY FOR THE SOCIO-ECONOMIC ASSESSMENT: A USEFUL WAY TO ASSESS PRIORITIES?}

${ }^{1} \mathrm{D}$ Corden, ${ }^{1}$ Mistry, ${ }^{2}$ Hutchings, ${ }^{3}$ Gorman Ng, ${ }^{3}$ Van Tongeren, ${ }^{3}$ Lamb, ${ }^{3}$ Sanchez-Jimenez, ${ }^{3}$ Shafrir, ${ }^{1}$ Sobey, ${ }^{2}$ Rushton, ${ }^{3}$ Cherrie. ${ }^{1}$ AMEC Environment \& Infrastructure UK Limited, London, United Kingdom; '2Department of Epidemiology and Biostatistics, Imperial College, London, United Kingdom; ${ }^{3}$ IOM, Edinburgh, United Kingdom

10.1136/oemed-2013-101717.192

Objectives To assess potential compliance costs and socio-economic benefits of potential future changes to the Carcinogens Directive for 25 substances.

Methods Drawing upon estimates of occupational exposure and health impact assessment, economic impacts of exposure due to disability and death were estimated under a 'do nothing' scenario. The value of disability and deaths avoided through possible reduced workplace concentrations were estimated based on value of life years lost, cost of illness and willingness to pay to avoid cancer.

Compliance costs of meeting possible amendments to the directive (stricter occupational exposure limits) based on the likely risk management measures needed in the workplace, were estimated for each relevant industry sector. This allowed key costs and benefits to be compared.

Results It was possible to quantitatively estimate both compliance costs and benefits in terms of reduced cancer impacts for around half of the 25 substances. These, along with other socioeconomic indicators of the potential impacts of further controlling workplace exposure were presented in a form intended to be compatible with an EU "Impact Assessment", which is required for any major new change in policy.

There are substantial uncertainties in any assessment such as this, including in approaches and data for valuing health impacts; numbers of people/firms affected; compliance methods and associated costs; amongst others.

Conclusions Assigning monetary values to the avoidance of cancer (and other health and environmental impacts) remains a controversial area. Nonetheless, the data developed during this study at least provide indications of the relative merits of targeting certain substances over others for possible future workplace exposure limits, based on a comparison of cancer avoided (and associated socio-economic benefit) with the compliance costs for affected industry. Given the large methodological uncertainties involved, the results are of most use in cases where the difference between costs and benefits is most pronounced.

\section{SHECAN - PRIORITISING ACTION ON OCCUPATIONAL CARCINOGENS IN EUROPE}

If W Cherrie, ${ }^{2}$ Hutchings, ${ }^{1}$ Gorman-Ng, ${ }^{3}$ Mistry, ${ }^{3}$ Corden, 'Lamb, 'Sanchez-Jimenez, ${ }^{1}$ Shafrii, ${ }^{3}$ Sobey, ${ }^{1}$ Van Tongeren, ${ }^{2}$ Rushton. 'Institute of Occupational Medicine, Edinburgh, United Kingdom; ${ }^{2}$ Imperial College, London, United Kingdom; ${ }^{3} A M E C$, London, United Kingdom

10.1136/oemed-2013-101717.193
Introduction In Europe the main legislation to ensure control of occupational carcinogens is Directive 2004/37/EC on the Protection of Workers from the Risks Related to Exposure to Carcinogens or Mutagens at Work. The EC DG Employment sponsored a socioeconomic, health and environmental analysis of possible changes to the Directive. This paper provides the background to the project and a broad overview of results.

Methods The project involved collecting available information about the circumstances of exposure for 25 substances. These data were used to assess the exposures, which in turn provided the basis for assessing the cancer burden from past and future use. Health costs and benefits were evaluated for no intervention and for the introduction of up to three possible Occupational Exposure Limits (OELs). Compliance costs were separately estimated.

Results Eleven of the substances were human carcinogens, four were probably carcinogenic and ten were possible human carcinogens. For six substances, there are more than a million workers in the EU currently exposed and for six substances there are less then 10,000 exposed. If there is no action, it was estimated there would be more than attributable 700,000 cancer deaths over the next 60 -years. However, there were only seven substances-OEL combinations where there was a substantial health benefit from introducing or reducing an OEL at the levels assessed. In general, total compliance costs were greater than monetized health benefits, mainly because of the delay in accruing benefits because of latency and the monetary value of these benefits being discounted in the calculation.

Discussion The strongest cases for the introduction of an OEL are for: RCS, chrome VI and hardwood dust. Other substances where the weight of evidence supports the introduction of a limit include: diesel engine exhaust emissions, rubber fume, benzo[a]pyrene, trichloroethylene, hydrazine, epichlorohydrin, o-toluidine, used engine oil and MDA.

\section{SHECAN - HEALTH AND SOCIO-ECONOMIC IMPACTS FOR CHANGES TO THE CARCINOGEN DIRECTIVE FOR SOME PROCESS GENERATED SUBSTANCES}

${ }^{1} \mathrm{M}$ J A van Tongeren, ${ }^{2}$ Hutchings, ${ }^{1}$ Gorman Ng, ${ }^{3}$ Mistry ${ }^{1},{ }^{3}$ Corden, Lamb, 'SanchezJimenez, ${ }^{1}$ Shafrir, ${ }^{3}$ Sobey, ${ }^{2}$ Rushton, ${ }^{1}$ Cherrie. ${ }^{1}$ Institute of Occupational Medicine, Edinburgh, United Kingdom; ${ }^{2}$ Imperial College, London, United Kingdom; ${ }^{3}$ AMEC, London, United Kingdom

\subsection{6/oemed-2013-101717.194}

Objectives To determine the health and economic impacts of introducing some process generated substances in the Carcinogen Directive.

Methods Health and economic impacts were estimated for introducing new OELs (diesel engine exhaust-DEE, silica, and rubber dust and fumes) or for applying best practice (mineral oils). Avoidable cancer cases and deaths were estimated for the year 2060, and monetized health benefit and cost for controlling exposure were compared.

Results The estimated health impact and associated cost for introducing a OEL for DEE100 $\mathrm{mg} \mathrm{EC} / \mathrm{m}^{3}$ was insignificant as, apart from in underground mines, only a small percentage of the EU workforce is currently exposed to higher levels. For silica, the impact of introducing new OELs of $0.05,0.1$ and $0.2 \mathrm{mg} / \mathrm{m}^{3}$ was estimated. The number of lung cancer deaths avoided was approximately 5300, 4900 and 4000, respectively. Associated net monetized health benefit was $€ 28-74 \mathrm{bn}$, $€ 26-68 \mathrm{bn}$ and $€ 21-56 \mathrm{bn}$, respectively. Estimated cost for 
introducing necessary control measures were $€ 34 \mathrm{bn}$, €19bn and $€ 10 \mathrm{bn}$, respectively. Introducing an OEL of $6 \mathrm{mg} / \mathrm{m}^{3}$ for rubber dust has only a minimal impact, while introducing an OEL of $0.6 \mathrm{mg} / \mathrm{m}^{3}$ for rubber fumes avoids approximately 50 cancer deaths per year. The net health benefit for implementing the rubber fume OEL is approximately $€ 579 \mathrm{~m}$ to $€ 1.2 \mathrm{bn}$, compared to cost for compliance of $€ 55-275 \mathrm{~m}$. In relation to mineral oils, we assumed that implementing best practice would prevent any cancers cases due to this exposure post 2040 , resulting in a net monetary health benefit of $€ 0.3-$ $1.6 \mathrm{bn}$, compared to a $€ 50-900 \mathrm{~m}$ required to implement best practice.

Conclusions The proposed changes for silica, rubber fumes and mineral oils will result in significant number of avoidable cancers, with monetized health benefit outweighing the cost of controlling exposure. For DEEthe proposed limit of $100 \mathrm{mg} \mathrm{EC} / \mathrm{m}^{3}$ will not lead to significant health benefits.

\section{Session: Mini symposium III: Workers compensation}

\section{WORK INJURY RISK BY TIME OF DAY IN TWO POPULATION-BASED DATA SOURCES}

${ }^{1}$ A Mustard, ${ }^{1}$ Chambers, ${ }^{2}$ McLeod, 'Bielecky, ${ }^{3}$ Smith. ${ }^{1}$ Institute for Work \& Health, Toronto, Canada; ${ }^{2}$ University of British Columbia, Vancouver, Canada; ${ }^{3}$ Monash University, Victoria, Australia

\subsection{6/oemed-2013-101717.195}

Mini-Symposium: Innovative uses of workers' compensation data: improving the impact.

Objective To estimate the rate of work injury over the 24 hour clock in two independent data sources for the Ontario labour force over a five year period 2004-2008.

Methods A cross-sectional, observational study of work-related injury and illness for a complete population of occupationallyactive adults 15-64. The two independent data sources were lost-time compensation claims and emergency department encounter records. Estimates of hours worked annually for the Ontario labour force by time of day, age, gender, and occupation were derived from population-based surveys.

Results The incidence of emergency department visits for work-related conditions was approximately $40 \%$ higher than the incidence of lost-time workers' compensation claims: 707,933 emergency department records and 457,141 losttime claims. For men and for women and across all age groups, there was an elevated risk of work-related injury or illness in the evening, night and early morning periods in both administrative data sources. This elevated risk was consistently observed across manual, mixed and non-manual occupational groups. The fraction of lost-time compensation claims that can be attributed to the elevated risk of work injury in evening or night work schedules is $12.5 \%$ for women and $5.8 \%$ for men.

Conclusions Despite the high prevalence of employment in nondaytime work schedules in the developed economies, the work injury hazards associated with evening and night schedules remains relatively invisible. This study has demonstrated the feasibility of using administrative data sources to enhance the capacity to conduct surveillance of work injury risk by time of day. More sophisticated etiologic research is needed to understand the specific mechanisms of hazards associated with non-regular work hours.

\section{THE IMPACT OF INJURY TYPE, HOSPITALISATIONS AND CHRONIC CONDITIONS ON AGE DIFFERENCES IN ABSENCE FROM WORK FOLLOWING INJURY}

${ }^{1}$ P M S Smith, ${ }^{2}$ Bielecky. ${ }^{1}$ Monash University, Melbourne, Australia; ${ }^{2}$ Institute for Work \& Health, Toronto, Canada

\subsection{6/oemed-2013-101717.196}

Objectives To examine the relative importance of pre-existing chronic conditions versus differences in injury type and subsequent hosptialisations on age differences in absence from work following a work-related injury.

Methods This study used short and long term disability claims (i.e. claims involving time away from work) reported to WorkSafe British Columbia (WSBC) linked with the British Columbia Discharge Abstract Database (DAD) and Medical Services Plan (MSP) at the individual level. We ran a series of nested regression models to examine the impact adjustment for eight different chronic conditions, and injury type and hosptialisations, on attenuating age differences in days of absence from work over the two year period following the injury. Analyses were run separately for men and women.

Results Among men, a clear direct gradient was observed for number of days absent from work and age. Among women there appeared a threshold effect, with no increase in days away from work among 45 - 54 and $55+$ year olds relative to 35 to 44 year olds. Pre-existing osteoarthritis, depression, and diabetes, as well as fractures, multiple injuries and hospitalisations were associated with longer absence from work among both men and women. Adjustment for injury type and hospitalisations attenuated differences across age groups among men by approximately $20 \%$. Adjustment for chronic conditions did not attenuate age differences in workers less than 35 years of age, and only marginally attenuated differences among older male workers.

Conclusions The relationship between age and absences from work following a work injury differs for men and women. Age differences in injury type and subsequent hosptialisations are more important pathways in explaining age differences in absence from work among men than pre-existing chronic conditions

\section{THE BENEFITS OF INTEGRATING COMPENSATION DATA WITH SURVEY DATA: THE PROSPECTIVE OUTCOMES OF INJURY STUDY EXPERIENCE}

R C Lilley, Derrett, Harcombe, Davie. Injury Prevention Research Unit, Dunedin, New Zealand

\subsection{6/oemed-2013-101717.197}

Objectives The Prospective Outcomes of Injury Study (POIS) is a prospective cohort study that has followed 2856 injured New Zealanders for 2 years. The study examines the influence of injury, rehabilitation, social, work and economic factors on vocational, functional and disability outcomes following acute injury in New Zealanders.

Methods POIS has collected data using personal interviews at 3, 5,12 and 24 month post-injury intervals on over 600 potential explanatory variables and three main outcomes. The cohort was recruited from the entitlement claimants register of New Zealand's monopoly universal accident compensation and 